\title{
STABILIZABILITY FOR NONLINEAR DIFFERENCE CONTROLS SYSTEMS WITH MULTIPLE DELAYS
}

\author{
KANIT MUKDASAI AND PIYAPONG NiAMSUP
}

\begin{abstract}
In this paper, we investigate the problem of stabilizability for nonlinear difference controls systems with multiple delays. We present a generalized discrete Gronwall's inequality for stabilizability analysis of this systems. Based on a new Gronwall's inequality, sufficient conditions for stabilizability of this systems are obtained. Numerical examples illustrate the results are given.
\end{abstract}

Mathematics subject classification (2010): 26D15, 26A51, 32F99, 41A17.

Keywords and phrases: Generalized Gronwall's inequality, nonlinear difference control systems with delays, stability, stabilizability, feedback control.

\section{REFERENCES}

[1] R. P. Agarwal, Difference Equations and Inequalities, Marcel Dekker, New York, 1992.

[2] P. Niams UP AND V. N. PHAT, Asymptotic stability of nonlinear control systems described by difference equation with multiple delays, Electron. J. Differ. Equ. 2000, 11 (2000), 1-17.

[3] V. N. Phat, Controllability of linear discrete-time systems with multiple delays on controls and states, Internat. J. Control 49, 5 (1989), 1645-1654.

[4] V. N. Phat, Constrained control problems of discrete processes, Series on Advances in Mathematics for Applied Sciences Vol. 42, World Scientific Publishing, London, 1996.

[5] V. N. PHAT, Asymptotic stability of nonlinear time varying differential equations, International Center for Theoretical Physics 123 (1997), 1-17.

[6] E. D. Sontag, Mathematical Control Theory, Springer-Verlag, New York, 1990.

[7] X. YANG AND Y. STEPANENKO, A stability criterion for discrete nonlinear systems with time delayed feedback, IEEE Trans. Automat. Control 39 (1994), 585-588. 